\title{
THE INFLUENCE OF THE TIME OF ANTIDOTAL TREATMENT ADMINISTRATION ON THE POTENCY OF NEWLY DEVELOPED OXIMES TO COUNTERACT ACUTE TOXIC EFFECTS OF TABUN IN MICE
}

\begin{abstract}
Jiři Kassa
University of Defence in Brno, Faculty of Military Health Sciences in Hradec Králové, Czech Republic: Department of Toxicology

Summary: 1. The influence of the time of administration of antidotal treatment consisting of anticholinergic drug (atropine) and newly developed oxime (K027 or K048) on its effectiveness to eliminate tabun-induced lethal toxic effects was studied in mice. 2. The therapeutic efficacy of antidotal treatment of tabun-induced acute poisoning depends on the time of its administration regardless of the choice of the oxime. 3. Our results show that both oximes studied (K027, K048) are able to sufficiently eliminate lethal effects of tabun. Nevertheless, their efficacy significantly decreases when they were administered $5 \mathrm{~min}$ after tabun poisoning. 4. The findings support the hypothesis that both newly developed oximes appear to be suitable oximes to counteract acute toxicity of tabun although their ability to eliminate lethal toxic effects of tabun significantly decreases with prolonged time interval between tabun challenge and antidotal treatment administration.
\end{abstract}

Key words: Tabun; K027; K048; Oximes; Acute toxicity; Mice

\section{Introduction}

The highly toxic organophosphorus compounds, called nerve agents (sarin, soman, tabun, cyclosarin or agent VX), belong to the most dangerous chemical warfare agents. Their acute toxicity is based on the irreversible inhibition of the enzyme - acetylcholinesterase (AChE; EC 3.1.1.7) and subsequent accumulation of the neuromediator acetylcholine at peripheral and central cholinergic sites $(19,23)$. AChE plays a key role in physiological function of the cholinergic nervous system and, therefore, its inhibition is lifeendangering factor. Inhibitory effect of nerve agents is based on phosphorylation or phosphonylation of serine hydroxy group at the esteratic site of the active site of the enzyme. Despite the long-term knowledgement of the basic mechanism of their acute toxicity, some nerve agents were found to be resistant to the standard antidotal treatment which consists of anticholinergic drugs to counteract the accumulation of $\mathrm{ACh}$ and oximes to reactivate nerve agentinhibited AChE (1,8,10). Tabun (O-ethyl-N,N-dimethyl phosphoramidocyanidate) is probably one of the most dangerous compounds among nerve agents, since its deleterious effects are extraordinarily difficult to counteract because of the existence of a lone electron pair located on an amidic group that makes the nucleophilic attack of oximes almost impossible $(2,4,5,7,14)$.
The ability of currently used monopyridinium (e.g. pralidoxime) and bispyridinium oximes (e.g. obidoxime, HI-6) in combination with atropine to eliminate acute toxic effects of nerve agents is rather low regardless of the choice of oxime $(7,13,14)$. Therefore, to find another bispyridinium oxime able to sufficiently reactivate nerve agent-inhibited AChE regardless of the type of nerve agent is still very important task for medicine to improve the efficacy of antidotal treatment of acute poisonings with nerve agents. Recently, two new bispyridinium oximes - K027 (1-[4hydroxyiminomethylpyridinium]-3-[4-carbamoylpyridinium] propane dibromide) and K048 (1-[4-hydroxyiminomethylpyridinium]-4-[4-carbamoylpyridinium] butane dibromide) were synthesized at our Department of Toxicology to increase the effectiveness of antidotal treatment to eliminate lethal toxic effects of tabun $(15,16)$. A comparison of the reactivating efficacy of currently available and newly developed oximes to reactivate tabun-inhibited $\mathrm{AChE}$ in vitro shows that the reactivation ability of both newly synthesized oximes is comparable to obidoxime and higher than the reactivation potency of pralidoxime and the oxime HI- 6 $(17,18)$.

It is known that the efficacy of antidotes in vivo depends not only on their reactivating efficacy but also on their therapeutic dose that is limited by their toxicity and on the time interval between nerve agent exposure and the admi- 
nistration of antidotes. It is expected that the shortening of the time between nerve agent poisoning and the administration of antidotes should bring higher potency of antidotes to eliminate acute lethal effects of tabun $(9,12)$. The present study investigates the influence of the time of antidotal mixture administration on the efficacy of newly developed oximes (K027, K048) in combination with atropine against tabun-induced acute poisoning in mice.

\section{Methods}

Male mice weighing between 18 and $22 \mathrm{~g}$ were obtained from Konárovice. The animals were maintained in an airconditioned room with light from 07.00 to $19.00 \mathrm{~h}$ and were allowed free access to standard food and tap water. The principles of laboratory animal care were followed and the handling of animals was made under the supervision of the Ethics Committee of Medical Faculty of Charles University and Faculty of Military Health Sciences in Hradec Králové

Tabun of $95 \%$ purity was purchased from Military Technical Institute Brno. Its purity was assayed by acidimetric titration. The oximes (K027, K048) of $98.0 \%$ purity were synthesized at the Department of Toxicology of the Faculty of Military Health Sciences in Hradec Králové. Its purity was analyzed using HPLC. All other chemicals and drugs of analytical grade were obtained commercially and used without further purification.

In our experiments, tabun-poisoned mice were treated intramuscularly (i.m.) with one of tested oximes at equieffective doses $\left(2 \% \mathrm{LD}_{50}\right)$ in combination with atropine $(21$ $\mathrm{mg} / \mathrm{kg}$ ) at 1,3 or 5 min after i. m. administration of tabun. The effectiveness of tested antidotal mixtures was evaluated by the assessment of the $\mathrm{LD}_{50}$ values and their $95 \%$ confidence limits using probit-logarithmical analysis of death occuring within $24 \mathrm{~h}$ after i.m. administration of tabun at five different doses with six mice per dose (22). The efficacy of tested antidotal mixtures was expressed as protective ratio $A\left(L_{50}\right.$ value of tabun in protected mice/ $L_{50}$ value of tabun in unprotected mice). The influence of the time of antidotal mixture administration was expressed as protective ratio $B\left(L_{50}\right.$ value of tabun in mice protected at 3 or 5 min following tabun poisoning/ $\mathrm{LD}_{50}$ value of tabun in mice protected at $1 \mathrm{~min}$ following tabun poisoning).

Statistical significance was determined by the use of Student's t-test and differences were considered significant when $\mathrm{p}<0.05$.

\section{Results}

The evaluation of therapeutic efficacy of antidotal mixtures consisting of studied oximes in combination with atropine administered at various time intervals following tabun challenge is summarized in Tables 1-2. These results show that the efficacy of tested antidotal mixtures is decreasing when the time interval between tabun poisoning and antidotal treatment is prolonged regardless of the choice of the oxime. The difference of the therapeutical efficacy of tested antidotal mixtures administered at various time intervals following tabun poisoning is significant in the case of usage of both oximes studied ( $p<0.05$ ) (Table $1-2)$. Nevertheless, the potency of K048 to eliminate tabun-induced acute toxicity decreases with the prolonged time interval between tabun poisoning and antidotal treatment slower compared to K027. While the significant decrease in the potency of $\mathrm{K} 027$ to eliminate tabun-induced acute toxicity with the prolonged time interval between tabun poisoning and antidotal treatment was demonstrated at 3 as well as 5 min compared to $1 \mathrm{~min}$ (Tab. 1), the potency of K048 sig-

Tab. 1: The influence of the time of administration of K027 in combination with atropine on its potency to eliminate acute lethal effects of tabun.

\begin{tabular}{|c|c|c|c|c|}
\hline Treatment & Time of treatment & $\mathrm{LD}_{50}(\mu \mathrm{g} / \mathrm{kg}) \pm 95 \% \mathrm{IS}$ & Protective ratio A & Protective ratio B \\
\hline \multirow{3}{*}{$\mathrm{K} 027+$} & - & $343.5(320.9-367.8)$ & - & - \\
\hline & $1 \mathrm{~min}$ & $576.0(493.0-673.1)^{*}$ & 1.68 & - \\
\cline { 2 - 5 } & $3 \mathrm{~min}$ & $454.8(422.8-489.1)^{* \mathrm{X}}$ & 1.32 & 0.79 \\
\cline { 2 - 5 } & $5 \mathrm{~min}$ & $450.7(424.4-478.6)^{* \mathrm{X}}$ & 1.31 & 0.78 \\
\hline
\end{tabular}

* significantly different from the untreated group at the level of $\mathrm{p}<0.05,{ }^{\mathrm{x}}$ significantly different from the group treated at 1 min following tabun poisoning at the level of $\mathrm{p}<0.05$.

Tab. 2: The influence of the time of administration of K048 in combination with atropine on its potency to eliminate acute lethal effects of tabun. Statistical significance - see Tab. 1.

\begin{tabular}{|c|c|c|c|c|}
\hline Treatment & Time of treatment & $\mathrm{LD}_{50}(\mu \mathrm{g} / \mathrm{kg}) \pm 95 \% \mathrm{IS}$ & Protective ratio A & Protective ratio B \\
\hline \multirow{3}{*}{ K048 + atropine } & - & $302.0(288.9-315.8)$ & - & - \\
\cline { 2 - 5 } & $1 \mathrm{~min}$ & $528.6(492.2-567.6)^{*}$ & 1.75 & - \\
\cline { 2 - 5 } & $3 \mathrm{~min}$ & $483.0(411.1-567.1)^{*}$ & 1.60 & 0.91 \\
\hline
\end{tabular}


nificantly decreases with the prolonged time interval between tabun poisoning and antidotal treatment at $5 \mathrm{~min}$ compared to 1 min only (Tab. 2).

To compare the potency of oximes, administered at the same time after tabun poisoning, to eliminate lethal effects of tabun, both oximes seem to be similarly efficacious reactivators of tabun-inhibited $\mathrm{AChE}$ in the elimination of tabun-induced acute toxic effects in mice, when they are administered at $1 \mathrm{~min}$ following tabun poisoning. On the other hand, K048 is demonstrated to be more efficacious reactivator of tabun-inhibited AChE in the elimination of tabun-induced acute toxicity when the antidotal treatment is administered later (at 3 or 5 min following tabun poisoning) (Tables 1-2).

\section{Discussion}

Nerve agents are still considered to be the most important chemical warfare agents. With the existing threat of the use of chemical weapons not only in military conflicts but also in terroristic attacks, the search for effective protection is the central concern of different laboratories both civilian and military $(4,20)$.

The effectiveness of antidotal treatment of acute poisoning with tabun is not sufficient regardless of the choice of the oxime because tabun-inhibited $\mathrm{AChE}$ is very difficult to reactivate $(3,7,10,21,24)$. The reason for the weak reactivation potency of the oximes is not the rate of aging of phosphonylated AChE that is relatively low (6) but the presence of lone electron pair located on an amidic nitrogen. The lone electron pair makes the nucleophilic attack very difficult (5). Due to the relatively low efficacy of antidotal treatment against tabun, it is necessary to optimize the dose of antidotes and the time of antidotal administration. The previous results confirm the importance of the dose of oximes to counteract lethal effects of tabun. Generally, low toxicity of oximes makes possible to use them at higher therapeutical doses (11). It was demonstrated that the potency of both newly developed oximes to eliminate tabun-induced lethal toxic effects in mice is comparable with the most efficacious currently available oxime trimedoxime when the oximes are administered at equieffective doses $\left(2 \% \mathrm{LD}_{50}\right)$ (12).

Our results confirm that the time af administration of antidotes following tabun poisoning is also very important. Commonly, the efficacy of antidotal treatment rapidly decreases when the time of its administration following tabun poisoning is prolonged (9). Nevertheless, the dependence of the efficacy of antidotes on the time of their administration is different for each oxime. While the therapeutic efficacy of $\mathrm{K} 027$ strongly depends on the time of its administration after tabun challenge and this dependence is comparable with mostly used oximes (obidoxime and the oxime HI-6) (12), the dependence is not so strong in the case of usage of K048 because the decrease in its potency to eliminate tabun-induced lethal toxic effects is not significant when
K048 is administered at 3 min following tabun challenge compared to $1 \mathrm{~min}$. To compare our results with previously published data dealing with currently available oximes (12), we can conclude that the potency of both newly developed oximes to eliminate tabun-induced lethal toxic effects in mice is comparable with the most efficacious currently available oxime trimedoxime when the oximes are administered at equieffective doses $\left(2 \% \mathrm{LD}_{50}\right)$ at 1 min following tabun challenge but they are less efficacious than trimedoxime when they are administered at 5 min following tabun poisoning. Thus, the potency of trimedoxime to eliminate tabun-induced lethal effects seems to be higher than the effectiveness of other currently available and newly developed oximes when they are administered in combination with atropine till 5 min following tabun poisoning.

In conclusion, our data indicate the necessity to administer the first dose of antidotes as soon as possible following exposure to nerve agents because the factor of the time seems to be very important for the efficacy of antidotal treatment to counteract their acute lethal effects.

\section{Acknowledgements}

The author thanks to Mrs J. Uhlírová for her technical assistance and help with statistical evaluation. The study was supported by the Grant of Ministry of Defence, OBVLAJEP20032.

\section{References}

1. Bajgar J, Fusek J, Vachek J. Treatment and prophylaxis against nerve agent poisoning. ASA Newslett 1994;94(4):10-1.

2. Cabal J, Bajgar J. Tabun - návrat po padesáti letech. Chem Listy 1999;93:27-31

3. Clement JG, Shiloff JD, Gennings C. Efficacy of a combination of acetylcholinesterase reactivators, HI-6 and obidoxime, against tabun and soman poisoning in mice. Arch Toxicol 1987;61:70-5

4. Dawson RM. Review of oximes available for the treatment of nerve agent poisoning. J Appl Toxicol 1994;14:317-31.

5. Eto M. Organophosphorus pesticides: Organic and biological chemistry. Cleveland: CRC Press Inc, 1976:142.

6. Jokanovic M. Anticholinesterase activity and delayed neurotoxic effects of tabun in hens. Vojvosanit Pregl 1993;50:451-56.

7. Jokanovic M, Maksimovic M, Kilibarda V, Jovanovic D, Savic D. Oxime-induced reactivation of acetylcholinesterase inhibited by phosphoramidates. Toxicol Lett 1996;85:35-9

8. Kassa J. A comparison of the therapeutic efficacy of conventional and modern oximes against supralethal doses of highly toxic organophosphates in mice. Acta Med (Hradec Králové) 1998;41(1):19-21.

9. Kassa J. Vliv doby podání antidotní terapie na její účinnost vůči toxicitě somanu u myši. Voj zdrav Listy 1999;68(4):93-5.

10. Kassa J. Review of oximes in the antidotal treatment of poisoning by organophosphorus nerve agents. J Toxicol-Clin Toxicol 2002;40(6):803-16.

11. Kassa J. Vliv dávky reaktivátorů acetylcholinesterázy na jejich účinnost při terapii otravy myší tabunem. Čes Slov Farm 2004;53(1):31-4

12. Kassa J. The influence of the time of antidotal treatment administration on its effectiveness against tabun-induced poisoning in mice. Acta Med (Hradec Králové) 2004:47(2):111-4.

13. Kassa J, Vachek J. A comparison of the efficacy of pyridostigmine alone and the combination of pyridostigmine with anticholinergic drugs as pharmacological pretreatment of tabun-poisoned rats and mice. Toxicology 2002;177:179-85.

14. Koplovitz I, Menton R, Matthews C, Shutz M, Nalls C, Kelly C. Dose-response effects of atropine and HI-6 treatment of organophosphorus poisoning in guinea pigs. Drug Chem Toxicol 1995;18:119-36.

15. Kuča K, Bielavský J, Cabal J, Bielavská M. Synthesis of a potential reactivator of acetylcholinesterase - 1-(4-hydroxyiminomethylpyridinium)-3-(carbamoylpyridinium)-propane dibromide. Tetrahedron Lett 2003;44: 3123-5.

16. Kuča K, Bielavský J, Cabal J, Kassa J. Synthesis of a new reactivator of tabun-inhibited acetylcholinesterase. Bioorg Med Chem Lett 2003;13: 3545-7. 
17. Kuča K, Kassa J. A comparison of the ability of a new bispyridinium oxime 1-(4-hydroxyiminomethylpyridinium)-4-(4carbamoylpyridinium) butane dibromide and currently used oximes to reactivate nerve agent-inhibited rat brain acetylcholinesterase by in vitro methods. J Enzyme Inhib Med Chem 2003; 18(6):529-35.

18. Kuča K, Kassa J. In vitro reactivation of acetylcholinesterase using the oxime K027. Vet Hum Toxicol 2004;46(1):15-8.

19. Marrs TC. Organophosphate poisoning. Pharmacol Ther 1993;58:51-66.

20. Ohtomi S, Takase M, Kumagai F. Sarin poisoning in Japan. A clinical experience in Japan Self Defense Force (JSDF) Central Hospital. Int Rev Arm Ser 1996; 69:97-102.

21. Puu G, Artursson E, Bucht G. Reactivation of nerve agent inhibited acetylcholinesterases by HI-6 and obidoxime. Biochem Pharmacol 1986;35:1505-10.

22. Tallarida R, Murray R. Manual of pharmacological calculation with computer programs. New York: Springer-Verlag, 1987:145

23. Taylor P. Anticholinesterase agents. In: The pharmacological basis of therapeutics (Hardman JG, Lombird LE eds.) New York: McGraw Hill, 1996:161-76.
24. Worek F, Widmann R, Knopff O, Szinicz L. Reactivating potency of obidoxime, pralidoxime, HI-6 and Hlö-7 in human erythrocyte acetylcholinesterase inhibited by highly toxic organophosphorus compounds. Arch Toxicol 1998;72 $237-43$

Submitted February 2005.

Accepted May 2005.

Doc. MUDr. Jiří Kassa, CSc.,

Faculty of Military Health Sciences, P.O. Box 35/T, 50001 Hradec Králové, Czech Republic. e-mail: kassa@pmfhk.cz 